Lepr Rev (1994) 65, 239-247

\title{
Disabilities of hands, feet and eyes in newly diagnosed leprosy patients in eastern Nepal
}

\author{
A. SCHIPPER,* W. J. LUBBERS, \\ MARGREET HOGEWEG†† \& \\ R. DE SOLDENHOFF $\S$ \\ $\S N S L / E a s t e r n$ Leprosy Control Project, PO Box 134, Biratnagar, \\ Nepal; $\dagger$ Department of Ophthalmology, State University of Leiden, \\ The Netherlands; $\ddagger$ Netherlands Leprosy Relief Organization NSL, \\ Wibautstraat 135, 1097 DN Amsterdam, The Netherlands; and \\ * State University of Groningen, The Netherlands
}

\section{Accepted for publication 28 February 1994}

Summary The objective of the study was to determine the magnitude of hand/ feet/eye disabilities in newly diagnosed leprosy patients by examining all newly diagnosed leprosy patients who presented at the Eastern Leprosy Control Project (supported by The Netherlands Leprosy Relief Association), made up of a regional clinic in Biratnagar and 5 mobile clinics in surrounding districts.

The study comprised of all new and previously untreated patients who presented at the clinics over a 10-week period who were diagnosed as leprosy sufferers.

Of the 260 leprosy patients examined $12(4 \cdot 6 \%)$ had sight-threatening lesions (lagophthalmos, iris involvement, corneal anaesthesia); 3 patients were blind due to cataract; $96 / 260$ patients $(37 \cdot 0 \%, 95 \%$ confidence interval $35 \cdot 0-43 \cdot 0 \%)$ had 1 or more disabilities of their hands and/or feet. The most frequently found disabilities were sensory loss of the hands and feet, claw hand and plantar ulcers. According to the WHO disability grading $60 \%$ had no disabilities, $19 \%$ had grade 1 and $21 \%$ had grade 2 disability.

Disability assessment is very important not only to evaluate the effectiveness of the control programme but also for the patient, whose most important worry is the stigmatizing deformities leprosy patients suffer. The earlier detection of sensory loss might reduce these secondary deformities.

\section{Introduction}

Leprosy patients are the same as everybody else in that they need their hands, feet and eyes in order to cope with daily living. Unfortunately, many patients still present to a clinic already suffering from limb damage in a disease which now can be well treated and

\footnotetext{
ๆ Correspondence: Department of Ophthalmology, Leiden University, PO Box 9600, 2300 RC Leiden, The Netilerlands.
} 
even cured. The 2 most important leprosy-related sight-threatening lesions are lagophthalmos and iridocyclitis. ${ }^{1}$

Disabilities occur because of the direct involvement of peripheral nerves which cause sensory loss and/or motor paralysis. Secondary deformities can also develop, e.g. contracture, ulcers and absorption of digits. With early detection many of these problems can be prevented.

According to the International Classification of Impairment, Disabilities and Handicaps (ICIDH), disability is defined as: 'any restriction or lack of ability (resulting from an impairment) to perform an activity in the manner considered normal." Sensory loss, by this definition, is an impairment, but for practical reasons we have used the term disability. The Eastern Leprosy Control Project (ELCP) is a joint project of the Nepalese Government with the Netherlands Leprosy Relief Association. The project covers 6 districts in the eastern terai (lowlands) of Nepal. An increasing number of patients come from India. From previous data and a subjective impression we presumed there would be more disabilities in the Indian patients.

The main clinic of the ELCP is in Biratnagar. There are 5 mobile clinics in the surrounding districts where the central staff goes once every month. In addition to these clinics there are 72 health posts where multidrug therapy (MDT) is provided for that area. District leprosy workers are responsible for supervising the resident multipurpose staff in these health posts.

\section{Patients and methods}

For 10 weeks between September and November 1992 we saw all new diagnosed leprosy patients who presented at the clinics.

After recording a registration number, age, sex, type of leprosy, duration of disease, district and presenting symptom, the eyes were examined.

Hands and feet were checked for deformities: clawing, drop foot, absorption, ankylosis, contracture and the presence of ulcers. The degree of deformity was measured and noted down. Voluntary muscle testing and sensory testing was then done by the physiotherapy technician, who also tested the following muscles: abductor digiti minimi, abductor pollicis, wrist extensors and dorsiflexors of the foot. For sensory testing a nylon filament was used on the hands and feet to test protective sensibility. Sensory loss was defined as missing more than 1 point of 12 test points on the hand and of 13 test points on the foot.

Disability grading was done according to the WHO 2 point scale (Table 1). ${ }^{3}$

\section{Results}

POPULATION

We examined 260 newly diagnosed leprosy patients; 219 in the main clinic in Biratnagar and 41 in the mobile clinics. There were 88 females and 170 males (sex ratio $1: 9$ ). The mean age was 34.5 years (females 32.9 and males 35.3 years). The patients from India tended to be older than the Nepalese patients (mean age 36 (India) and 32 (Nepal) years, statistically significant, 2-tailed $t$-test, $p<0 \cdot 05$ ). 
Table 1. WHO disability grading 2-point scale

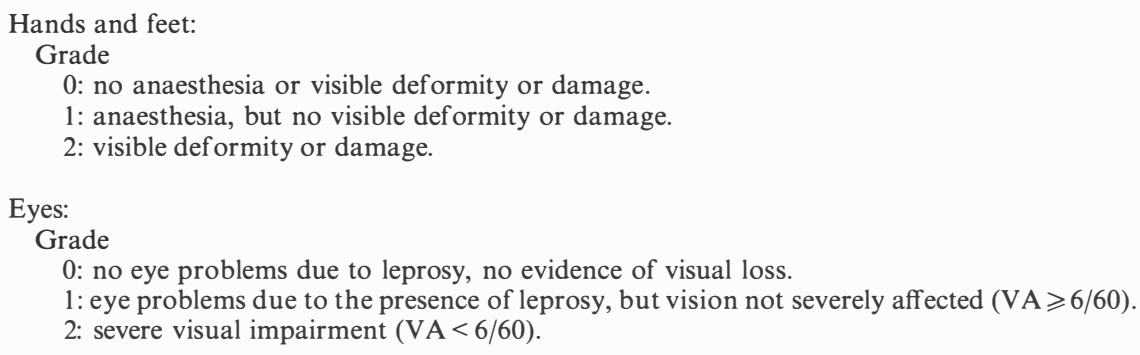

For age distribution see Figure 1.

Of the total population investigated $46.5 \%$ came from Nepal. In the main clinic in Biratnagar the percentage of Indian patients was $63 \cdot 5 \%$.

In total, $41 \%$ of the patients had tuberculoid leprosy (TT) or borderline-tuberculoid leprosy (BT) and these were treated with the 6-month WHO multidrug regimen. The other $59 \%$ had BT + , mid-borderline leprosy (BB), borderline-lepromatous leprosy (BL), lepromatous leprosy (LL) and pure neural leprosy (PNL) and were treated with a 24-month WHO regimen (Figure 2).

BT + is defined in Nepal as having BT with at least 3 body areas involved. ${ }^{4}$

There is a significant difference in the distribution of leprosy type between females

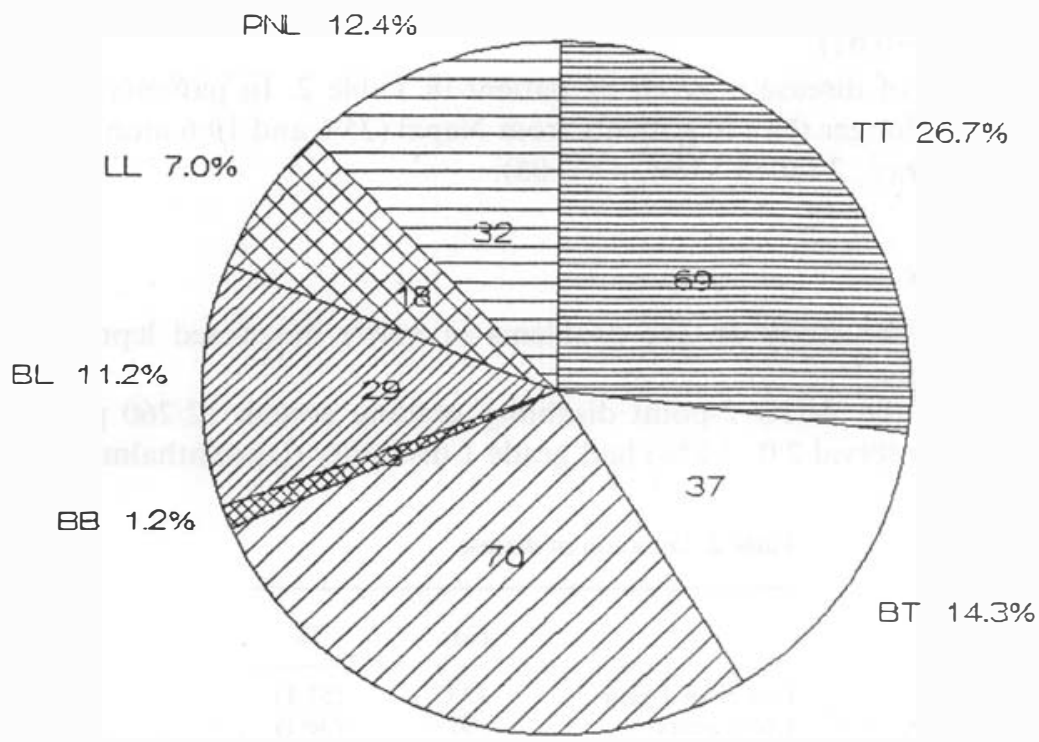

$\mathrm{BT}+27.1 \%$

$$
n=258
$$

Figure 1. Age distribution. 


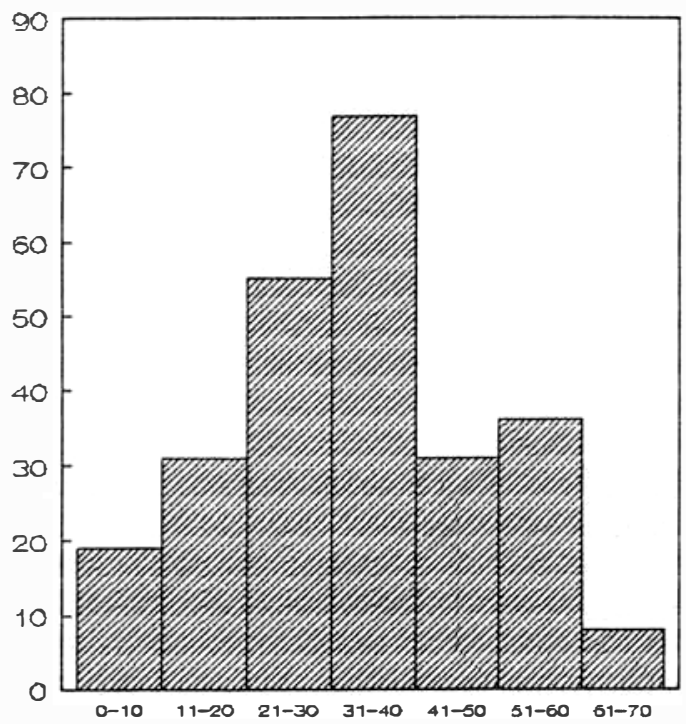

Figure 2. Type of leprosy. TT, tuberculoid; BT, borderline tuberculoid; BT +, borderline tuberculoid with 3 or more body parts involved, Nepalese definition; ${ }^{4} \mathrm{BB}$, borderline; BL, borderline lepromatous; LL, lepromatous; PNL, pure neural leprosy.

and males, with $52 \%$ of females in the TT,BT group against $34 \%$ of males (statistically significant, $\left.\chi^{2}, p<0 \cdot 01\right)$.

The duration of disease is given by patient in Table 2 . In patients from India the mean duration is longer than in patients from Nepal (25.6 and 19.6 months, statistically significant difference, 2 -tailed $t$-test, $p<0.05$ ).

EYE-DISABILITIES

The outcome of the study on eye problems in newly diagnosed leprosy patients is presented elsewhere. $^{5}$

According to the WHO 2-point disability grading system $12 / 260$ patients $(4.6 \%$, $95 \%$ confidence interval $2 \cdot 0-7 \cdot 2 \%$ ) had grade 1 disability (lapophthalmos, iris involve-

Table 2. Duration of disease

\begin{tabular}{lrr}
\hline & No. & $\%$ \\
\cline { 2 - 3 } & 133 & $(51 \cdot 1)$ \\
Less than 1 year & 91 & $(35 \cdot 1)$ \\
1 to 5 years & 14 & $(5 \cdot 8)$ \\
More than 5 years & 22 & $(8 \cdot 5)$ \\
Unknown & 260 & $(100.00)$ \\
\hline Total & & \\
\hline
\end{tabular}


Table 3. Disabilities (306 disabilities in 96 patients)

\begin{tabular}{lccc}
\hline & Unilateral & Bilateral & Total $(\%$ of 260$)$ \\
\hline Hand & & & \\
$\quad$ Clawing & 22 & 7 & $29(11 \cdot 0)^{*}$ \\
Contracture & 5 & 4 & $9(3 \cdot 5)$ \\
Ulcer & 6 & & $6(2 \cdot 3)$ \\
Absorption & 11 & 3 & $14(5 \cdot 4)$ \\
Sensory loss & 45 & 21 & $66(25 \cdot 0)$ \\
Foot & & & \\
$\quad$ Drop foot & 5 & 1 & $6(2 \cdot 3)$ \\
$\quad$ Ulcer & 16 & 6 & $13(5 \cdot 0)$ \\
Absorption & 8 & 5 & $58(22 \cdot 3)$ \\
Sensory loss & 22 & 36 & \\
Eye & & & $9(3 \cdot 5)$ \\
$\quad$ Lagophthalmos & 9 & - & $3(1 \cdot 2)$ \\
Iris involvement & 3 & - & \\
\hline
\end{tabular}

* Numbers in parentheses are percentages.

ment with VA $\geqslant 6 / 60)$. Grade 2 disability was found in $13 / 260$ patients $(5 \cdot 0 \%, 95 \%$ confidence interval $2 \cdot 3-7 \cdot 7 \%$ ) with V A $<6 / 60$ in 1 or 2 eyes. All were caused by cataract. More patients had impaired vision caused by cataract but they are not included in grade 1 disability by the WHO standard.

\section{DISABILITIES OF HANDS/FEET}

No disability or muscle weakness was found in $60 \%$ of patients. Only muscle weakness, without sensory loss or other disabilities, was found in $3 \%$ of patients; 96 patients $(36.9 \%$, $95 \%$ confidence interval $30 \cdot 9-42 \cdot 9 \%$ ) had 1 or more of the disabilities listed below in Table 3 .

Table 4 shows the number of disabilities per patient. When there was only 1 disability this was most often sensory loss.

In total, 66 patients $(26 \%, 95 \%$ confidence interval $20 \cdot 6-31 \cdot 4 \%)$ had 1 or more motor nerves involved (voluntary muscle testing score less than 5). The distribution in the 135 nerves concerned in these 66 patients is as follows: facial $7 \%$, ulnar $51 \%$, median $29 \%$, radial $4 \%$ and peroneal $9 \%$. The total number of nerves involved per patient is given in Table 5 .

According to WHO disability grading $60 \%$ of patients had no disability, $19 \%$ had grade 1 and $21 \%$ had grade 2 disability. The mean age of these 3 groups is respectively 32,39 and 36 years. The WHO disability grading does not seem to be higher in Indian patients (Table 6, no significant difference, $\chi^{2}, p>0 \cdot 1$ ).

Proportionally, $73 \%$ of females had no disability (WHO grade 0 ), against $53 \%$ of males. There were more disabilities (64\%) in the multibacillary group of patients, against $27 \%$ with disablities in the paucibacillary group (Table 7 , statistically significant, $\chi^{2}, p<0 \cdot 01$ ).

The disabilities listed in Table 3 will now be discussed more extensively.

\section{CLAWING AND CONTRACTURES}

There were 29 patients $(11 \%)$ with 1 or 2 claw hands, giving 36 claw hands in all. In 18 
Table 4. Number of disabilities

\begin{tabular}{lrr}
\hline $\begin{array}{l}\text { No. of } \\
\text { disabilities }\end{array}$ & $\begin{array}{c}\text { No. of } \\
\text { patients }\end{array}$ & \multicolumn{1}{c}{$\%$} \\
\hline 0 & 163 & $62 \cdot 7$ \\
1 & 36 & $13 \cdot 8$ \\
2 & 20 & $7 \cdot 7$ \\
3 & 9 & $3 \cdot 5$ \\
4 & 8 & $3 \cdot 1$ \\
5 & 6 & $2 \cdot 3$ \\
6 & 8 & $3 \cdot 1$ \\
7 & 3 & $1 \cdot 2$ \\
8 & 3 & $1 \cdot 2$ \\
9 & 2 & $0 \cdot 8$ \\
10 & 1 & $0 \cdot 4$ \\
14 & 1 & $0 \cdot 4$ \\
\hline Total & 260 & $100 \cdot 0$ \\
\hline
\end{tabular}

Sum of above disabilities: absorption hand, absorption foot, clawing hand, contracture hand, ankylosis hand, ulcer hand, ulcer foot, sensory loss in hand, sensory loss in foot; each

patients (20 hands) there was only ulnar clawing, which did not exceed 60 degrees. In 11 patients ( 16 hands) there was ulnar/median clawing exceeding 70 degrees, of which 10 hands had contractures ( 7 patients), and 1 patient with only mild clawing also had a contracture.

\section{ULCERS}

The 6 hands with an ulcer all had partial or complete sensory loss -4 out of 6 were on the dorsum of the fingers. Of 26 feet with ulcers, 20 had complete sensory loss and 6 had partial sensory loss. Ulcers were most frequently on the metatarsal heads (Table 8).

Table 5. Number of muscles involved

\begin{tabular}{lrr}
\hline $\begin{array}{l}\text { No. of muscles } \\
\text { involved }\end{array}$ & $\begin{array}{c}\text { No of } \\
\text { patients }\end{array}$ & $\%$ \\
\hline 0 & 198 & $76 \cdot 2$ \\
1 & 30 & $11 \cdot 5$ \\
2 & 18 & $6 \cdot 9$ \\
3 & 4 & $1 \cdot 5$ \\
4 & 4 & $1 \cdot 5$ \\
5 & 4 & $1 \cdot 5$ \\
6 & 2 & $0 \cdot 8$ \\
\hline Total & 260 & $100 \cdot 0$ \\
\hline
\end{tabular}

Sum of facialis, abductor digiti minimi, abductor pollicis, wrist extensors, dorsiflexors foot; each left or right. $\mathrm{Max}=10$. 
Table 6. WHO disability grade by localization $(n=247)$

\begin{tabular}{llll}
\hline WHO grade & India & Nepal & Total \\
\hline 0 & $80(58 \cdot 8)^{*}$ & $68(61 \cdot 3)$ & $148(59 \cdot 9)$ \\
1 & $27(19 \cdot 9)$ & $20(18 \cdot 1)$ & $47(19 \cdot 0)$ \\
2 & $29(21.3)$ & $23(20 \cdot 8)$ & $52(21 \cdot 1)$ \\
\hline Total & $136(55 \cdot 1)$ & $111(44 \cdot 9)$ & $247(100 \cdot 0)$ \\
\hline
\end{tabular}

Difference not significant, $\chi^{2}, p>0 \cdot 1$.

* Numbers in parentheses are percentages.

\section{ABSORPTION}

Of 17 hands (14 patients) with a shortening of the fingers 3 were caused by an accident unrelated to leprosy, 10 hands had only slight absorption (tips of fingers or one phalanx) and 4 had more severe absorption with more than 1 phalanx missing. Of 18 feet (13 patients) with absorption, 1 was caused by an accident. There were 10 feet with a slight absorption of toes and 8 with severe absorption.

\section{SENSORY LOSS}

There were 90 patients (36\%) with sensory loss of hands and/or feet. Of the 66 patients $(25 \%)$ with a sensory loss of hands ( 78 hands) there was in 25 hands a partial loss, in 38 hands a loss in the ulnar region and in 24 hands a complete sensory loss; 58 patients $(22 \%)$ had sensory loss of feet (94 feet), 44 feet with partial and 50 feet with complete sensory loss.

\section{DROP FOOT}

Drop foot is defined as a voluntary muscle testing (VMT) score of 3 (or less) for the dorsiflexors if the foot can just be moved against gravity (or less). There were 6 patients with drop foot, 1 of them with bilateral drop foot. In 3 feet there was a complete paralysis.

Table 7. WHO grading in pauci- and multibacillary patients (missing 16)

\begin{tabular}{lccr}
\hline WHO grade & PB & MB & Total \\
\hline 0 & $120(73 \cdot 2)^{*}$ & $28(35 \cdot 9)$ & 148 \\
1 & $21(12 \cdot 8)$ & $21(26 \cdot 9)$ & 42 \\
2 & $23(14 \cdot 0)$ & $29(37 \cdot 2)$ & 52 \\
\hline Total & $164(100)$ & $78(100)$ & 242 \\
\hline
\end{tabular}

Difference statistically significant, $\chi^{2}, p<0 \cdot 01$.

* Numbers in parentheses are percentages. 
Table 8. Ulcers on feet

\begin{tabular}{lr}
\hline & No. \\
\hline Metatarsal heads & 18 \\
Dig. 1 & 3 \\
Dig. 2-5 & 3 \\
Heel & 6 \\
Midfoot & 2 \\
Dorsum/Lat malleolus & 4 \\
\hline
\end{tabular}

\section{Discussion}

We examined 260 new patients. The fact that we could not examine the new patients in the health posts might mean that our population has more complications than the mean leprosy population of eastern Nepal. We do not think this difference is significant in new patients when selection has not yet taken place.

The mean age of our patients was less than that in other studies, ${ }^{6,7}$ which was to be expected because other studies have usually been done in resettlement villages or leprosaria.

\section{DISABILITIES}

Of our population $36.9 \%$ (95\% confidence interval $30.9-42.9 \%$ ) had 1 or more disabilities. A similar study in Nigeria recorded $38.8 \%$ in a hospital-based population. ${ }^{6}$ Reports from Malawia and Tanzania give figures of $21.9 \%$ and $30 \cdot 0 \%$, also in new patients. ${ }^{8}$ This lower figure is probably due to the higher prevalence of tuberculoid leprosy in Africa in comparison with Asia, while disabilities are found more frequently in lepromatous patients. ${ }^{7}$ More male than female patients suffer from disabilities, as reported by others, perhaps because the percentage of men suffering from lepromatous disease is significantly higher. ${ }^{6,7}$

Sensory loss was the most common disability, accounting for $59 \cdot 1 \%$ of the total number of disabilities. When only 1 disability was present this was most often sensory loss. This means that some of the secondary disabilities can be prevented with health education and regular check-ups.

Apart from sensory loss the most frequent disabilities were claw hand $(11.8 \%)$ and plantar and palmar ulcers $(11 \cdot 2 \%)$. In Molai these were also the 3 most frequently found disabilities (sensory loss $35 \%$, claw hand $13 \%$, ulcers $17 \%$ ). ${ }^{6}$ The high figure of sensory loss in our study might be due to our definition of sensory loss.

Although we expected more disabilities in the patients coming from India, this could not be confirmed. Neither was there a greater percentage of patients with disabilities, nor more disabilities per patient. The self-history of disease according to the patient is not very reliable because of their subjective interpretation.

\section{Conclusions}

The importance of careful disability measuring at intake in a leprosy control programme 
cannot be overestimated, because it is an indication of effectiveness. Also, from the patient's viewpoint, the deformity caused by leprosy is the part of the disease which affects his or her life most, because of the stigmatizing and disabling effect. Some of the early detected disabilities may still be suitable for treatment by steroids.

Because a high percentage of the disabilities is sensory loss in hands and feet, which can be the cause of secondary deformities, early detection and frequent monitoring of disabilities may prevent secondary deformities. Early detection and early treatment does not always mean secondary deformities can be prevented, but they can be minimized. ${ }^{8}$

\section{References}

1 Editorial. Ocular complications in leprosy. The Lancet, 1992; 340: 642-3.

2 Brandsma JW, Heerken YF, Lakerveld-Heyl, Mischer van Ravensberg CD. The international classification of impairments, disabilities and handicaps in leprosy control projects. Le pr Rev, 1992; 63: 337-44.

3 WHO: a guide to leprosy control. 2nd edition. World Health Organization. Geneva 1988.

${ }^{4}$ Brakel WH van, Soldenhoff R de, McDougall AC. The allocation of leprosy patients into paucibacillary and multibacillary groups for multi drug therapy, taking into account the number of body areas affected by skin, or skin and nerve lesions. Lepr Rev, 1992; 63: 231-46.

5 Lubbers WJ, Schipper A, Hogeweg M, Soldenhoff R de. Eye disease in newly diagnosed leprosy patients in Eastern Nepal. Lepr Rev, 1994; 65: 231-38.

6 Iyere BB. Leprosy deformities: experience in Molai Leprosy Hospital, Maiduguri, Nigeria. Lepr Rev, 1990; 61: 171-9.

7 Fine PEM. Leprosy, the epidemiology of a slow bacterium. Epidemiologic Review, 1982; 4: 161-88.

8 Watson JM. Disability control in a leprosy control programme (editorial). Lepr Rev, 1989; 60: 169-77. 